same genus. Hippagres is closely allied to Crentella, as the latter is represented by C. glandzula of Totten and, indeed, I cannot detect any character to distinguish them generically. These agree in shape, sculpture, hinge, muscular impressions and inflexion of the beaks. The genus Verticordia of S. Wood is very different and belongs to another family, viz. that of Lyonsin.

Mr. Arthur Adams informs me that he has several Japanese species, which he believes are also found in the Mediterranean, and $I$ have identified many British species with those of North Japan.

J. GWYN JEFFREYS

\section{An Oversight by Faraday}

IT is not often that Faraday committed an oversight ; but such I think he must have done in his well-known paper concerning the existence of a limit to vaporisntion. ("Experimental Researches in Chemistry and Physics," p. I19. *) Faraday showed experimentally, that mercury emitted no appreciable vapour below $20^{\circ} \mathrm{F}$. and accounted for this on the ground that "the elastic force of any vapour which the mercury could have produced at that temperature, was less than the force of gravity upon it and that, consequently, the mercury was then perfectly fixed." He adds, "I think we can hardly doubt that such is the case, at common temperatures, with respect to silver and with all bodies which bear a high temperature without appreciable loss by volatilisation, as platina, gold, iron, nickel, silica, alumina, charcoal, \&c., and that, consequently, at common temperatures, no portion of vapour rises from these bodies or surrounds them."

Has not Faraday overlooked the fact that though gravity might pievent the rise of vaponr, it would assist the fall of vapour from the sides or under surface of a body suspended in vacuo? If Faraday's theory had any grounds in truth, it would be possible to distil a substance from above downwards by the sole force of gravity, but I know of no experiment to support the idea. Were all the other forces which could act upon the molecules, exactly balanced in unstable equilibrium, the force of gravity might undoubtedly upset this equilibrium, so that vapour would be produced from the under surface of a suspended solid when it could not be produced from the upper surface. But a very slight estimation of the forces which may enter into such a problem, shows how unlikely it is that the case could ever happen.

I do not mean to say that the force of tenacity of solid substance, is identical with that which is opposed to volatilisation; but it is possibly comparable with it in amount. Now a copper wire, having a section of one square millimetre, will bear a weight of 90 lbs. and this force of tenacity only acts between portions of metal in absolute contact and continuity. Compare now the weight of a film of copper, say $\frac{1}{200}$ part of a millimetre thick, with the force by which it adheres to the remainder of the mass of copper with which it is continuous. Taking the specific gravity at S.9, the weight will be, per square millimetre, 0.000089 gramme; the force which would be required to tear it from the remainder of the mass would be, for the same surface, $40819^{\circ}$ grammes. The force of tenacity, therefore, exceeds the weight rather more than $450,000,000$ (450 million) times. This seems to show that the molecular forces which tend to maintain the integrity of a solid metal, are almost infinitely greater than the gravitation of the same molecules towards the earth. To cause these molecules to fly off in fiee vapours, we must call in the aid of forces of heat, electricity, or chemical affinity which can cope with the prodigious force of solid cohesion. It is practically impossible that we should ever meet with a case, where these forces were so exactly balanced that the exterior force of gravity, many million times less in amount, should produce a perceptible disturbance.

These considerations do not, however, appear to affect the validity of Wollaston's speculations concerning a definite limit to the earth's atmosphere as caused by the gravity of the aërial particles.

\section{Where are the Nebulæ?}

I AM maffectedly glad to find that one whose opinion has such weight as Mr. Spencer's must have, should have anticipated me in the matters to which he directs your attention in his interesting letter. There can be no question as to his priority; since in 1863 I had not only formed no views respecting the nebule; but had no further knowledge of astronomy than I derived from a very faint recollection of what I had learned in a hasty two hours' perusal of Goodwin's Astronomy (Course of

* Phil. Trans. 1826, p. $4^{84}$
Mathematics) the night before our examination on the subject in the "Thiee days" at Cambridge.

In considering the subject of the nebulæ recently, however, the points touched on by Mr. Spencer had not escaped me. In five papers in the Intellectual Observer and Student called "Notes on Nebulæe," "Notes on Star-streams," and "A New Theory of the Universe" (three parts), I touched on these and many other proofs that the nebula are not external galaxies; but part and parcel of the sidereal system.

I have since found that Dr. Whewell, in his "Plurality of Worlds," had adopted the same view. But as a matter of fact, we owe the enunciation of clearly convincing evidence respecting the true nature of the nebulae to Sir John Herschel ; while Sir W. Herschel, when as yet the available evidence was incomplete, indicated his belief that the Orion nebula (amongst others) is within the sidereal system.

Strangely enough, the point first dwelt on by Mr. Spencer was boldly quoted by the Rev. C. Pritchard (V.P.R.A.S.) as a proof that the nebulæe are external galaxies, immediately after I had read my communication on the distribution of the nebulae to the Astronomical Society. I asked at once if we were to regard those vacant spaces as the spy-holes, so to speak, of the sidereal system, through which alone the nebula could be hopefully looked for and Mr. Pritchard said "Yes." Mr. Stone, also, pointed out subsequently, that the glare from the stars might elsewhere obliterate the nebula (at least the fainter ones) from view. This would be a point to be attentively considered were it not that in the Nubecula we have evidence that the glare from many stars does not obliterate faint nebulax.

The second point dwelt on by Mr. Spencer affords a remarkable instance of the way in which considerations that should be perfectly obvious, escape even practised astronomers. Strangely enough, I dwelt on this point, only three days ago, in a letter I addressed (not for publication) to the editor of the Spectator. It is commonly unclerstood and stated that telescopes which are only just able to show stars of the tenth, twelfth, or fourteenth magnitude as the case may be, are able to exlibit the component stars of certain external galaxies, which must (according to the theory) be thousands of times farther from us than the fourteenth magnitude stars. Not a thought has been given to the obvious conclusion that these component stars, to be thus visible, must be millions of times larger than the members of our galaxy.

In a letter addressed last August to Sir John Herschel (a portion of the answer to which was quoted in my article in NATURE for January 27), I pointed out half-a-century of reasons for believing that the sidereal system is differently constituted than has been supposed and that the nebule are not external to it. (This would have involved an egregiously long letter had I been writing to an ordinary correspondent, but in the actual case a few words served sufficiently to indicate each reason.) These reasons were not interdependent-each afforded good and most afforded perfectly sufficient ground for rejecting the accepted theory. In his repiy, Sir Jolnn (always kind, courteous and encouraging) was good enough to speak of the "number and variety of the striking facis brought together and the evident bearing of a large proportion of them on the great problem offered by the sidereal system to man's contemplation." Amongst the facts which afford the strongest evidence of all, are two I left unnoticed in my late paper; viz., (I) the relatively large proper motion of the fainter stars and (2) the drift of whole groups of stars in a definite direction. These facts apply to the structure of the sidereal system, rather than to the position of the nebula ; but, as a matter of fact, the two matters are so closely related, that evidence bearing on one carries with it conclusions affecting the other also.

February 4

\section{Analogy of Colour and Music}

I FIND in your number of January I3 an interesting paper by Mr. Barrett on the Correlation of Colour and Sound. It seems to me that Mr. Barrett clepreciates the phenomenon of Newton's rings by saying that the "connection between the relative spaces occupied by each colour and the relative vibrations of the notes of the scale" ... " camnot be more than a coincidence." The diameters of the rings are functions of the wave-lengths and, therefore, expressions of a physical condition. Mr. Barrett's own process is, to say the least, very rough and, after taking " the mean of two limits," wather wide apart for the length of the waves of each colour, he obtains a series of numbers which 